\title{
Discurso sobre a criança: a questão do ludicismo
}

Angela Baalbaki (UERJ)

\section{Resumo}

Este artigo tem como objetivo investigar o funcionamento do discurso sobre a criança. Baseia-se na fundamentação teórica da Análise do Discurso de linha francesa, especificamente, a tradição inaugurada por M. Pêcheux. Noções como a de categoria criança e de ludicismo foram propostas na tentativa de compreender a constituição dos sentidos do sujeito-criança que circulam em nossa sociedade. As reflexões aqui tomadas indicam que o discurso sobre a criança é atravessado por um ludicismo que implica as relações estabelecidas com o jurídico, dissimulando, pela brincadeira, pelo jogo, o próprio jurídico. Também é característico do ludicismo uma projeção do futuro da criança, o vir-a-ser-sujeito.

Palavras-chave: Discurso sobre criança; categoria; ludicismo 


\section{Considerações iniciais}

Na Análise de Discurso de orientação francesa, os conceitos teóricos têm seu valor enquanto operadores na análise. Assim sendo, nas análises realizadas a partir desse quadro teórico, tratamos tanto dos dispositivos teóricos quanto dos procedimentos analíticos. Vale destacar que um princípio constitutivo da Análise do Discurso (AD) é a vinculação desses dois dispositivos. E é exatamente a vinculação entre teoria e prática que faz com que a disciplina se movimente. Tal movência não se dá em virtude de uma superação teórica, mas de adequação ao material de análise. Com o intento de trabalharmos no interior desse batimento, propomos um novo dispositivo teórico: o ludicismo.

É importante registrar que em $\mathrm{AD}$ o dispositivo teórico refere-se a todo seu quadro teórico. Tal dispositivo se particulariza frente aos conceitos mobilizados em cada pesquisa. $\mathrm{O}$ conjunto de conceitos trabalhados em vista à pergunta, aos objetivos e à natureza de material de análise compõe o que podemos chamar de "dispositivo analítico" (ORLANDI, 2000). Apresentamos, a seguir, algumas noções centrais dos dispositivos analíticos, ou seja, aqueles conceitos que fundamentam a nossa pesquisa a respeito do funcionamento do discurso sobre a criança.

Em seu livro Análise Automática do Discurso, Pêcheux (1997), ao definir discurso como "efeito de sentido entre locutores", distanciou sobremaneira o objeto teórico da AD da noção de mensagem atrelada ao tradicional esquema de comunicação, entendida como transmissão de informação. O objeto teórico com o que se preocupa a Análise do Discurso não é uma simples superação da linguística saussuriana, haja vista que não é um objeto linguístico, mas um objeto sócio-histórico, no qual o linguístico é pressuposto. Trata-se, efetivamente, de outro objeto teórico.

O recorte teórico que relaciona língua e discurso não pode ser confundido como continuidade da dicotomia língua/fala, tal como entendido por Saussure, na medida em que a noção de discurso não pode ser posta como uma realização individual do sistema linguístico. Nessa perspectiva, língua e discurso recebem outra significação, pois "nem o discurso é visto como uma liberdade em ato, totalmente sem condicionantes linguísticos ou determinações históricas, nem a língua como totalmente fechada em si mesma, sem falhas ou equívocos" (ORLANDI, 2000, p. 22).

A língua é condição de possibilidade do discurso. A relação existente entre processos discursivos e a língua repousa na materialidade da língua. Em outros termos, a língua constitui o lugar material, a base na qual se realizam os processos discursivos, fonte de produção de efeitos de sentido.

O discurso, por sua vez, não pode ser considerado um conjunto de frases portadoras de várias significações. Ele é um processo que se desenvolve em determinadas conjunturas só- 
cio-históricas, é o lugar em que a ideologia se materializa e estabelece relação com a língua, produtora de sentidos por e para sujeitos. Se a definição de discurso com que trabalhamos é a de efeito de sentido entre interlocutores, como falar de sentidos em uma teoria como a Análise do Discurso?

Consideramos a relação dos sujeitos e dos sentidos afetados pela língua e pela história. Cumpre destacar que sujeito e sentido constituem-se mutuamente no discurso. Ou nos dizeres de Orlandi, "ao produzir sentido, o sujeito se produz, ou melhor, o sujeito se produz, produzindo sentido" (ORLANDI, 2004, p. 56-57).

O processo histórico de constituição de evidência do sentido faz com que o sentido pareça estar fixado como essência das palavras, como se houvesse um elo que ligasse palavras e seus sentidos e apagasse as determinações históricas e sociais. Em uma perspectiva materialista, os sentidos não existem em si mesmos, não há uma relação transparente com a literalidade, mas são determinados por posições ideológicas no processo sócio-histórico. A literalidade não pré-existe, ela é um efeito de discurso. Esse é o ponto em que destacamos/inserimos o nosso trabalho, visto que não é possível identificar apenas um sentido para o termo criança.

Os sentidos que se apresentam como literais são produtos da história, e não o resultado de uma relação natural entre palavras e coisas do mundo. Em determinadas condições de produção, há a dominância de um dos sentidos, mas outros sentidos possíveis ressoam. Por isso, podemos afirmar que toda produção discursiva é investida em processos de significação variados. É preciso ressaltar que "se os sentidos podem sempre ser vários e podem ser outros, isso não significa dizer que o sentido possa ser qualquer um" (ORLANDI, 2004, p. 56-57 grifos da autora). O sentido dominante - ao ser legitimado - fixa-se ideologicamente como sendo o único, o centro; cristaliza-se. Daí, o efeito de literalidade.

De forma a historicizar a categoria criança, procedemos à análise dos diferentes materiais que compuseram nosso arquivo. Observamos que a construção de sentidos sobre criança pode ser depreendida em diferentes textualizações, desde tratados até declarações internacionais. A hegemonia do sentido de criança como um vir-a-ser sujeito aponta para a primazia do discurso sobre a criança.

Nosso corpus está organizado em torno dos séculos XVIII a XX, e os materiais de linguagem analisados são: artigos acadêmicos; trechos de tratados sobre infância, declaração mundial. Pretende-se com esse corpus buscar regularidades dispersas, comparar diferentes séries temporais, verificar como textos dialogam e apontam para redes de sentidos. Tais regularidades são identificadas na confluência da constituição (interdiscurso) e da formulação (intradiscurso). É a memória discursiva que possibilita a constituição dos dizeres. No movimento, ou melhor, por entre lembrança e esquecimento, que a memória é atualizada no fio de 
cada discurso. E aí (no fio discursivo) podemos encontrar as regularidades. Em outros termos, como se dá o jogo entre o mesmo e o diferente, ou seja, como certos sentidos de criança se mantêm ou se deslocam em função de diferentes condições de produção e da relação mantida com a memória discursiva.

\section{A criança e o ludicismo}

Circulam, em nossa sociedade, enunciados que supostamente definem como é ser criança, quando é ser criança, como tratar a criança, enfim, o que é ser criança. Circulam enunciados que apontam para a criança em formação: uma "semente-de-adulto". Na formulação de tais discursos, a imagem produzida é da falta. Podemos sublinhar que é uma criança falada pela insuficiência, por seu caráter incompleto em relação ao ponto almejado de vir a ser adulto. Talvez resida aí a pretensa curiosidade da criança posta pelos divulgadores: a de ser adulto.

Sabemos que a constituição do sujeito funda-se em sua relação com a linguagem, com a história, com a ideologia. Ao ser apresentada como um sujeito-falado, a criança tem sua imagem construída como se estivesse fora das determinações sócio-históricas e de sentido, tornando-se uma evidência. Nesse movimento de produção de evidência, podemos falar em um gesto de produção de uma categoria: a categoria criança. Devemos explicitar que tomamos o termo categoria tal como em Haroche (1992). Inspirada nos textos de Foucault, a autora destaca que um mecanismo coercitivo do Estado para fins de poder ("governo pela individualização") classifica os indivíduos em categorias. Em outros termos, "identifica-os, amarra-os, aprisiona-os em sua identidade. Aprisionamento na identidade que é obrigatoriamente exibido por cada um..." (HAROCHE, 1992, p. 21).

A criança, em uma suposta identidade, é representada como una, indivisível, ou melhor, como uma criação da modernidade tomada como "uma mônada - unidade substancial ativa e individual; presente, no limite, em todos os seres infantis da espécie humana: sempre a mesma; sempre igual, inquebrantável, inamovível, irredutível" (BOTO, 2002, p. 57). Essa condição de identidade produz a ilusão de que o mundo da criança é algo totalmente desvinculado das relações de produção e reprodução social. Do nosso ponto de vista, a criança não é uma categoria de conteúdo a ser preenchida, mas uma construção sócio-histórica.

Em uma perspectiva contrária ao antiespontaneísmo pedagógico, Nosella (2002) afirma que "a criança não é um homem adulto em potencial, não é semelhante a um novelo que já contém 'enrolada' toda a linha da vida e que, portanto, basta puxar pela ponta que tudo se desenvolve naturalmente" (NOSELLA, 2002, p. 156). Concordamos que a criança seja um sujeito historicamente determinado, pois não só tomamos a criança como um sujeito 
Parece-nos que a postura encontrada em "Emílio" foi de encontro ao movimento de moralização promovido pelos reformadores da Igreja católica no final do século XVII. As concepções difundidas pela reforma atribuíam à criança a tendência natural ao mal. Nessa conjuntura, a educação foi instituída como principal garantia de ordem pública (VORCARO, 2004). social e histórico, mas, sobretudo, simbólico. Tomamos a criança em sua condição de sujeito discursivo.

Vale ressaltar que a categoria criança foi produzida nas e pelas relações postas com o sujeito do capitalismo. Diz-nos Smolka (2002) que esse sujeito - o homo racionalis, sujeito da razão - em um esforço de teorização sobre si mesmo, teoriza sobre a criança, ou melhor, cria evidências. Para a autora, o homo racionalis

\begin{abstract}
imerso em uma intricada trama, sujeito ao conjunto de ideias, de significações, de esquecimentos historicamente produzidos, a-sujeitado à ideologia, à linguagem, ao inconsciente. É nessa tensão que encontramos a criança como produção humana. Produção certamente orgânica, biológica. Mas não meramente (re)produção da espécie. Produção fundamentalmente simbólica e discursiva. Nomear a criança, conceituar a infância, ou teorizar sobre o desenvolvimento ... faz parte de um gesto de conhecimento tornado possível pela produção de significação característico do próprio Homo - Faber, Simbolicus, Duplex (SMOLKA, 2002, p.123-124).
\end{abstract}

Em suma, para falar sobre divulgação científica para a categoria criança, é preciso, primeiramente, compreender como a criança foi construída no interior da ideologia capitalista e quais foram os efeitos produzidos por seu evidenciamento.

Vale registrar que, etimologicamente, o termo criança, de acordo com Mauad (2004), tem sua origem associada ao ato de criação. Da mesma forma que os animais têm crias, a criança é a cria da mulher. Destacando que 'criar' refere-se a nutrir, alimentar, fazer crescer. Diz a autora que somente "nas primeiras décadas do século XIX, que os dicionários assumiram o uso reservado da palavra 'criança' para a espécie humana" (MAUAD, 2004, p. 140). Podemos dizer que o uso reservado, ou melhor, a passagem de cria animal para criança humana se deu em um período no qual o homem torna-se sujeito e objeto do saber (FOUCAULT, 2007).

Historicamente, a criança é falada pelo adulto. Isso significa dizer que, em diferentes conjunturas históricas, a criança é falada diferentemente na relação com o adulto. E mais, cada conjuntura histórica delimita essa relação.

De forma a compreender a historicidade que funda os sentidos de criança como um vir-a-ser-sujeito, apresentamos, em linhas gerais, o tratado pedagógico de Rousseau, cujo título é Emílio, ou da educação. Esse tratado foi publicado no século XVIII e talvez seja o primeiro tratado sobre a educação da criança. Nele, Rousseau versa sobre como deveria ser a educação das crianças tomadas como seres bons ${ }^{1}$ por natureza: "Nascemos fracos, precisamos de força; nascemos carentes de tudo, precisamos de assistência; nascemos estúpidos, precisamos de juízo. Tudo o que não temos ao nascer e de que precisamos quando grandes nos é dado pela educação" (ROUSSEAU, 2004, p. 9). Observamos em Rousseau o papel da educação frente à criança. É a educação 
que tornará esse sujeito antes fraco, carente e estúpido em um sujeito bom: um sujeito submisso às leis. Um sujeito que deve ser individualizado pelo Estado (por meio de suas instituições, no caso, a escola).

Pode-se observar, nesse extenso tratado, que a criança é compreendida por uma clivagem racional: o que a separa do adulto é a "idade da razão". Para Rousseau, a criança apreenderia a realidade à sua volta mediante imagens e sensações, sendo "as primeiras sensações das crianças [...] puramente afetivas" (ROUSSEAU, 2004, p. 49). A criança, para Rousseau, é inocente, sensível e tornar-seia um bom homem (bom sujeito?) pela educação. Aliás, completa Rousseau, "na ordem natural, sendo os homens todos iguais, sua vocação comum é a condição de homem" (ROUSSEAU, 2004, p. 14). Além da clivagem cartesiana, encontramos em Emílio o ideário iluminista da igualdade entre os homens; igualdade que está na base das relações jurídicas do capitalismo. Podemos dizer que o tratado de Rousseau foi fundado na dimensão de um Estado civil.

Em suma, em Emílio encontramos um determinado modo de ver, pensar, conceber a criança. Seus pressupostos tornaram-se evidências no discurso pedagógico ocidental, no qual sentidos sobre a criança e a educação foram naturalizados. No entanto, Emílio é uma das várias textualizações da discursividade que funda a categoria criança.

Para compreendermos como determinados sentidos foram constituídos na obra de Rousseau, faz-se necessário verificar como operou a constituição desse sujeito de direitos civis. Para tal, recorremos a Haroche (1992) que, em seu livro Fazer dizer, querer dizer, ocupa-se em realizar uma análise da história dos mecanismos envolvidos na passagem do sujeito religioso - assujeitado à ideologia cristã; um sujeito marcado por uma "subordinação ao texto e ao dogma" (HAROCHE, 1992, p.57) - para o sujeito jurídico. Cabe dizer que essa passagem não foi automática. Sua constituição tem uma história cujo momento crucial localiza-se no período que vai do século X ao século XIII (HAROCHE, 1992). Um período marcado por transformações no sistema econômico então vigente (o sistema feudal) cuja influência propiciou o enfraquecimento do poder da Igreja.

Se até o século XI havia uma sujeição pessoal (relação de vassalagem), nos séculos seguintes, tomou lugar, progressivamente, uma relação centrada nas relações econômicas. Passava-se de uma economia agrícola de subsistência a uma economia de manufatura. Com a sedentarização do comércio (instauração do corporativismo), e a emancipação dos camponeses (reivindicações de direitos e deveres e liberdades) - decorrentes do processo de urbanização, começa a haver uma intervenção cada vez maior do jurídico sobre o religioso. Foi o início do processo de "autonomização" do sujeito. Esse sujeito aparece "aliando obrigação 
econômica à liberdade jurídica; o sujeito torna-se, assim, livre para se obrigar" (HAROCHE, 1992, p. 69).

Imputa-se, no processo de constituição do sujeito jurídico, uma necessidade de clareza da linguagem, de banir a ambiguidade, objetivando melhorar a comunicação, fazendo-se "entender, mas não compreender" (HAROCHE, 1992, p. 84). No cerne da problemática da ambiguidade colocada como um problema de língua está a inteligibilidade do texto legal, que se pretende compreensivo. Instaura-se uma demanda pela clareza, ou melhor, desambiguização e logicidade na relação do sujeito com a língua; uma relação que exige transparência, objetividade, literalidade.

Voltando à discussão sobre a constituição do sujeito jurídico, Orlandi (2007a) aponta que o discurso humanista da reforma expressão da dominação progressiva do sistema jurídico sobre a ordem religiosa, enfraquecida por sucessivas crises, já anunciava o individualismo burguês do século XIX. Com esse sujeito, diz a autora, "não se trata de questionar, mas de entender para se submeter. Há dois polos que se desenham: o da objetividade (caracterizada pelo rigor) disjunto do polo da subjetividade (caracterizado pela indeterminação e o inefável)" (ORLANDI, 2007a, p. 14).

Segundo Haroche (1992), o assujeitamento (sujeito jurídico) apoia-se no rigor, na precisão, na transparência, na letra, na técnica: no polo da objetividade. Estabelece, com esse assujeitamento, uma relação entre o direito e o saber: "o direito ao saber, à inteligibilidade, à curiosidade, à abertura, em resumo, todos nascidos da troca e da expansão econômica" (HAROCHE, 1992, p.84). O polo da subjetividade marca o sujeito pela imprecisão, pelo direito à indeterminação.

O século XVIII, marcado pela revolução científica, consagra o polo da objetividade, em detrimento do polo da subjetividade. $O$ processo de desenvolvimento científico e tecnológico produziu um sujeito submetido às leis do Estado, leis que se impuseram entre o sujeito e o saber, configurando-o como poder. Para Orlandi (1999), o processo de constituição do sujeito jurídico atinge seu ápice no século XIX, século do individualismo triunfante.

O sujeito jurídico é constituído por um equívoco: é interpelado pela ideologia capitalista de autonomia, liberdade e unicidade e é individualizado pelo Estado, o que o torna responsável por si próprio e por seu dizer. Do ponto de vista da Análise do Discurso, é um sujeito dividido que funciona no registro jurídico, com direitos e deveres, como senhor de sua vontade, de suas intenções e responsável por seu dizer, ao mesmo tempo em que funciona por uma memória de dizer à qual ele mesmo não tem acesso e é determinado pela sociedade e pela história (ORLANDI, 2007a).

E como se deu a passagem da ordem religiosa à ordem jurídica em relação à criança? Todos os acontecimentos ligados ao desenvolvimento do Direito e à laicização abalaram o mecanismo 


\footnotetext{
2 Ariès aponta também que essa valorização se deu com o surgimento de uma nova modalidade familiar: a família nuclear burguesa, trazendo as mulheres e as crianças para o domínio privado e os homens para o domínio público. Destacamos que esse é um modelo burguês de família e não do proletariado. Segundo Boto (2002), a relação mais importante da família medieval dava-se com a solidariedade da linhagem. A criança era considerada um rebento do tronco da comunidade e sua sociabilidade era comunitária. Com o individualismo burguês, a família nuclearizou-se e emancipou-se dos vínculos comunitários, a criança passou a ser considerada no interior das famílias e as relações parentais sobrepuseram-se. $\mathrm{O}$ declínio da esfera pública e o aumento de processos de intimidade (domínio privado) no âmbito familiar não podem ser desvinculados dos ideais de igualdade, liberdade e defesa da propriedade. As novas relações parentais possibilitaram, dentre outros, a transmissão de propriedade. É possível pensar que a herança passa a ser tematizada para além da propriedade, como por exemplo, a herança genética e cultural. Sobre a última, muito em voga nos séculos XX e XXI, o dever do Estado de proporcionar educação passa a ser quase exclusivamente da família.
}

de dominação do sujeito religioso. E, consequentemente, a relação que se mantinha com a criança.

A historiografia sobre a criança indica distinções no tratamento dispensado à criança na Idade Média e na Modernidade. Um dos trabalhos mais expoentes (e também muito criticado) é o desenvolvido por Ariès (1981). Em suas teses sobre a evolução da intimidade, Ariès considera que, somente no século XVII, a valorização da criança ${ }^{2}$ teve início. Para o autor, dois fatores levaram à valorização: a emergência da vida privada (como por exemplo, a nova configuração das moradias, com cômodos separados) e o surgimento de escolas (na modernidade, considerado o lugar de preparação do futuro adulto). De fato, o autor enuncia vários aspectos relacionados em torno da valorização da criança: diminuição da mortalidade infantil, sobretudo, com desenvolvimento da pediatria; desenvolvimento da tipografia (aumentando a demanda de leitores alfabetizados); e o desenvolvimento da pedagogia (com o surgimento de novas correntes teóricas e novos métodos de ensino para aprendizagem de leitura).

Todas as questões apontadas por Ariès (1981) relacionam-se à ascensão da burguesia e à constituição de um novo modo de produção. Do nosso ponto de vista, todas essas mudanças, com o avanço do aparelho jurídico, propiciaram a constituição do sujeito-de-direito. Tendo como base a formação do sujeito jurídico, podemos pensar sobre o gesto de produção da categoria criança. Um aspecto que precisa ser retomado nessa discussão são as leis para a proteção da infância. O modo de pensar a criança (visto que ela não fala, mas é falada, e deve ser protegida) acolhe os mecanismos de individualização impostos pelo Estado por meio de suas instituições. No caso da criança, veremos que a instituição escolar é a requisitada para tal fim (ao menos nos em um primeiro momento).

Anteriormente, utilizamos "individualização" conforme comparece na obra de Haroche (1992). Acreditamos que tal termo seja tomado como um processo de responsabilização do sujeito. Cabe ressaltar que a partir desse ponto, tomamos a noção de individualização tal como definida por Orlandi (2002). Para a referida autora, a ilusão idealista do sujeito como origem em si mesmo está assentada no desconhecimento de um duplo movimento na compreensão da subjetividade. Em um primeiro movimento, ocorre a interpelação do indivíduo, afetado pela língua e pela ideologia, em sujeito. Diga-se, a forma-sujeito histórica, ou seja, o sujeito capitalista caracterizado como sujeito jurídico. Em um segundo movimento, há individualização dessa forma-sujeito pelo Estado por meio de suas instituições, o que resulta em um indivíduo ao mesmo tempo responsável e dono de sua vontade. Para a autora, nesse duplo movimento "há o caráter irrecorrível do assujeitamento [...] e a possível resistência do sujeito aos modos pelos quais o Estado o individualiza" (ORLANDI, 2002, p. 72). 
Acreditamos que uma distinção entre a definição de cada uma das autoras em tela é a consideração da noção como um movimento da subjetividade que prevê, sobretudo, a resistência.

No final do século XVII, o humanismo decorrente da reforma de Igreja instituía a educação como a principal garantia de ordem pública. Percebemos que o individualismo burguês não surgiu fora de um controle sobre o corpo - as práticas de civilidade. Com os processos de individualização da vida, tais práticas passaram a ser realizadas pela escola. Em um novo lugar social, a criança passou a ser educada e tornou-se "aluno", como também passou a ser objeto de intervenções (como no século seguinte, em que foi protagonista do tratado de Rousseau). A civilidade teve importante papel no processo de invenção da moderna categoria criança e do que foi chamado "especialização do mundo da criança".

A especialização do mundo da criança ocorreu paulatinamente e vários foram os aspectos envolvidos. Para Ariès (1981), a imposição de uma essência inocente à criança consolidou a mudança no tratamento da mesma. Se anteriormente fala-se sobre sexo diante das crianças, com as reformas moralizantes promovidas pelos reformadores da Igreja, no final do século XVII, os educadores objetivavam incutir um sentimento de culpa nas crianças. Aliadas à inocência, são ressaltadas, nesse período, a fragilidade e debilidade da criança. Peres (1999) sustenta que até o século XVII não havia uma separação entre jogos e brincadeiras infantis e aquelas destinadas aos adultos. Segundo a autora, com o movimento moralizante, muitos dos jogos passaram a ser considerados imorais. A preocupação era preservar a moralidade e educar as crianças. Com as restrições morais impostas, as crianças passaram a se dedicar às brincadeiras e às distrações diferentes das adotadas pelos adultos. Em relação aos contos de fada, no século XVII, aparecem as versões como, por exemplo, as compiladas por Perrault. Conta-nos Bettelheim (1991) que, em sua origem, na Idade Média, os contos de fada eram destinados a entreter a corte. Eram contos que continham doses de sexo, violência, arrogância. Segundo Peres (1999), Perrault higieniza, moraliza esses contos, torna-os "próprios" para as crianças. Com esse gesto de moralização, Perrault funda a literatura infantil, uma literatura destinada a incutir princípios morais. Para Ariès (1981), os adultos perderam, na segunda metade do século XVII, o interesse pelos contos de fada. Havia nesse período dois interesses pela literatura: publicações mais sérias destinadas aos adultos e outras às crianças e ao povo.

A inserção da criança no aparato escolar, contudo, deu-se lentamente, sobretudo, para a classe proletária. Com a implantação da revolução industrial no final do século XVIII, a criança tornou-se, desde a mais tenra idade, "trabalhador". 
Nosella (2002) ressalta que, na fase inicial do capitalismo, o que corresponderia à fase inicial de acumulação de capital, a criança exerceu importante função. Tamanha foi sua importância que, pela primeira vez na história, a sociedade a teria tomado a sério mesmo que fosse, infortunadamente, para "explorá-la como força de trabalho produtiva barata" (NOSELLA, 2002, p. 133). Entretanto, com o desenvolvimento científico e tecnológico, a mão de obra infantil tornou-se obsoleta, pois sua maior contribuição passou a ser considerada no futuro. A criança passa de mão de obra barata para assunto de Estado. Tal passagem não se faz fora do jurídico.

Segundo Donzelot (apud VORCARO, 2004), as primeiras leis sociais regulavam o tempo de trabalho das crianças nas fábricas. A partir de 1840, várias normas protetoras da infância se multiplicaram, culminando na primeira Declaração dos Direitos da Criança (1924). Posteriormente, outras declarações foram promulgadas, sendo a declaração de 1959 a adotada pela Assembleia das Nações Unidas. Esse interesse pela criança é resumido por Nosella (2002):

só quando a criança se tornou força de trabalho interessante para o capital, começou a ser contemplada pela legislação de forma autônoma de sua família. Foi uma legislação que, num primeiro momento, obrigou a criança a trabalhar e, mais tarde, após o desenvolvimento da grande indústria, a liberou do trabalho [...] a questão da guarda e da educação das crianças tornou-se assunto principal no debate político, na legislação social e nas reformas escolares desde o final do século XVIII praticamente até hoje (NOSELLA, 2002, p. 134).

A Declaração dos Direitos da Criança se constitui de um preâmbulo e de dez princípios - partes da textualização do discurso de direitos humanos. O preâmbulo dá sustentação à declaração, uma vez que retoma os pactos de sua elaboração. A retomada de outros discursos que a fundam é materializada pelo termo "visto". ("VISTO que os povos das Nações Unidas"; "VISTO que as Nações Unidas"; "VISTO que a criança"; "VISTO que a necessidade de tal proteção"; "VISTO que a humanidade deve à criança o melhor de seus esforços"). Em seu princípio primeiro diz-se que "Todas as crianças, absolutamente sem qualquer exceção, serão credoras destes direitos, sem distinção ou discriminação por motivo de raça, cor, sexo, língua, religião, opinião política ou de outra natureza, origem nacional ou social, riqueza, nascimento ou qualquer outra condição, quer sua ou de sua família". Em “Todas as crianças" o efeito de sentido é o de afirmar a igualdade entre as crianças. Funciona, de forma pressuposta, o jurídico, produzindo um efeito de pré-construído: diante da declaração supõe-se que todas as crianças são iguais. Tanto o preâmbulo quanto os princípios se organizam em torno da proteção à criança, que em decorrência de sua imaturidade física e mental, inspira cuidados especiais. À criança devem ser garantidos educação, saúde e diversão. O tra- 
balho é proibido "antes de idade mínima conveniente" (Princípio $9^{\circ}$ ). Mas o que seria conveniente? Parece-nos que o "conveniente" é ditado pelas condições econômicas e políticas de cada país.

A criança-de-direitos é uma construção do final do século XIX e, como autora menciona acima, permanece nos dias atuais. A instância de criança-de-direitos está relacionada às revoluções liberais, tanto a Americana quanto a Francesa. O discurso dos direitos das crianças tem seus sentidos sustentados no discurso dos direitos humanos, o qual se funda no discurso da pretensa igualdade (que de fato, apaga as diferenças). Trata-se da categoria-criança sendo produzida como um sujeito de direitos humanos.

Orlandi (2007b) destaca que o discurso dos direitos humanos silencia a diferença de classes: fonte de desigualdades. Logo, "a diferença de classes precisa do discurso da igualdade perante a lei" (ORLANDI, 2007b, p. 305). Esse discurso da igualdade também silencia a desigualdade entre crianças. Ressaltamos que a mão de obra barata da criança não foi banida do sistema de produção capitalista. Nas regiões mais pobres, em países periféricos, há bolsões de miséria onde se coaduna o trabalho infantil. Então, o direito à educação e a proibição do trabalho infantil - previstos na Declaração dos Direitos da Criança - não são iguais para todos. Os direitos são destinados igualmente a todas as crianças para melhor excluir muitas. Esse é um equívoco constituído na e pela conjuntura burguesa. O lugar de destaque da educação - que supostamente dá a todos as mesmas oportunidades - e as leis de proteção à criança são produzidos para lidar com a ambiguidade instaurada pelo sistema capitalista que se organiza e se estrutura em torno do lucro e não da dignidade humana.

Se, no início do capitalismo, o pátio da fábrica foi o lócus da criança proletária, com o desenvolvimento da industrialização e da tecnologia, ele foi transferido para a escola. Assim sendo, nos séculos XIX e XX, a criança ganhou um novo lugar social. Para Boto (2002), a construção da categoria aluno foi a grande referência de compreensão da criança construída na modernidade. De acordo com o autor, "a estrutura ritual do colégio contribui para a 'construção do objeto infância'; ou, mais precisamente, para a criação da categoria criança-aluno" (BOTO, 2002, p. 33).

As colocações de Boto (2002) apontam para a relação existente entre os processos de escolarização e a produção da concepção de infância nas sociedades modernas. Diríamos a concepção de infância de uma determinada classe. Pensar a criança por meio da categoria "criança-aluno" e não pela categoria "criança-trabalhador", por exemplo, possibilita-nos compreender como a criança é individualizada pela escola.

No acolhimento da infância pelo Estado, este monopolizou técnicas disciplinares e saberes pedagógicos necessários à escolarização. A monopolização dos saberes não somente possibilitou a delegação da educação das crianças ao Estado, como também 
3 Smolka (2002) destaca a teoria evolucionista de Darwin como um registro das relações de herança genética e experiência adquirida, bem como na busca daquilo que diferencia o homem dos animais. Cabe ressaltar que, em outra condição de produção, foi um registro que também tematizava a civilidade. A Teoria de Darwin desembocou um interesse pela mente humana desde a infância até a fase adulta. É nesse contexto que se pretende colocar a criança como a repetição da história do homem ou seja, que "a ontogênese repete a filogênese" (SMOLKA, 2002, p. 114) Vorcaro (2004) afirma que a posição evolucionista chegou a isolar as fases do desenvolvimento humano recapitulando o desenvolvimento da criança à evolução da espécie humana: "o domínio dos instintos vitais corresponderia à animalidade; à imaginação supersticiosa infantil equivaleriam as culturas primitivas; e o estado de observação reflexiva madura repetiria a racionalidade da civilização" (VORCARO, 2004, p. 29). a diluição da circulação dos saberes na sociedade. Em primeiro momento buscou-se a organização da turma e depois outras técnicas de disciplinarização. Uma dessas técnicas foi, segundo Foucault (2006), o ensino coletivo:

Nas escolas do século XVIII os alunos também estavam aglomerados e o professor chamava um deles por alguns minutos, ensinava-lhe algo, mandava-o de volta, chamava outro, etc... Um ensino coletivo dado simultaneamente a todos os alunos implica uma distribuição espacial. A disciplina é, antes de tudo, a análise do espaço. É a individualização pelo espaço, a inserção dos corpos em um espaço individualizado, classificatório, combinatório. (FOUCAULT, 2006, p. 106)

Esse espaço individualizado obedece a um princípio de visibilidade que isola o sujeito de todos os outros (HAROCHE, 1992), passando, dessa forma, o sujeito interpelado pela ideologia a funcionar como um indivíduo, um autômato.

Ao longo do século XIX, foram desenvolvidos vários métodos de ensino para as crianças. Era o momento de instauração de uma pedagogia "racional", preocupada com a racionalização do ensino. Em um novo tratamento dado à infância, não só a organização do espaço foi preponderante, mas também metodologias "renovadoras" baseadas em investigações ${ }^{3}$ teóricas sobre a criança (análise de funções mentais e de sua fisiologia, leis de seu desenvolvimento). As metodologias foram definidas em função de necessidades específicas: suportar as exigências da modernidade - industrialização crescente e avanços científicos e tecnológicos. Se, nos séculos XVI e XVII, a escola era o lugar da apreensão da civilidade, no século XIX, ela se tornou o lugar para preparar a crianças para as novas imposições sociais. Muitas dessas metodologias basearam-se na promessa ao divertimento, ao lúdico (contrapondo-se ao trabalho). E essa foi uma nova forma de solidificar a categoria criança - unívoca, inquebrantável, como afirma Boto (2002), tornando-a uma especificidade dessa etapa da vida.

Por ser a categoria criança enunciada na tensão da relação entre adulto e não-adulto, ela é significada pela falta, pelo o que ela ainda não é, ou seja, um vir-a-ser. A categoria criança não é tomada como um sujeito responsável, mas construída historicamente no interior do aparato jurídico, que a põe como garantia de vir-a-ser-sujeito. Nessa garantia há uma determinação da implicação do futuro que recobre a atualidade - sempre evanescente - da criança. A especularização, a futuralização da humanidade e a correlação de potencialidade permitem produzir um imaginário que coloca a criança como sendo o futuro da nação.

De forma a compreender a garantia jurídica de vir-a-serbom-sujeito atrelada à categoria criança, consideramos relevante pensá-la por meio do ludicismo que é aí instaurado. Cabe destacar que o termo foi inspirado no termo juridismo tal como cunhado por Lagazzi (1988). Sucintamente, podemos dizer que o juridismo 
4 Para Foucault (2010), a criança, como os loucos, os criminosos, os doentes, os desviantes, estariam sob mecanismos de poder que exercem sobre eles efeitos de repressão, de desqualificação, de desconhecimento, de privação; em suma, "o arsenal dos conceitos e mecanismos negativos da exclusão" (FOUCAULT, 2010, p.38). é uma definição que desvela estreiteza das relações de poder interpessoais cotidianas. O jurídico corresponde à legislação concebida por uma sociedade, o que configura o sistema jurídico. Já o juridismo é compreendido como "intertextualidade da instância jurídica, do Direito" (LAGAZZI, 1988, p. 46). O juridismo está atrelado ao dizer cotidiano que implica o jurídico sem explicitá-lo, ou melhor, como a relação dos direitos e deveres deriva para o senso comum. Isso significa que "se mantém uma certa mobilidade (flexibilidade) entre direitos e deveres, responsabilidades, cobranças e justificativas no cotidiano. [...]. A implicitação é o ponto de sustentação da ordem cotidiana, porque é por onde o simbólico se mantém" (LAGAZZI, 1988, p. 46-47).

Intentamos averiguar como a relação da criança com o jurídico é promovida, visto que não há como não se assujeitar à forma histórica do sujeito de direito. Em outros termos, nosso objetivo é analisar, do ponto de vista discursivo, como o jurídico instaura a relação com a criança, produzindo para tal a categoria vir-a-ser-sujeito. Mais especificamente, procuramos compreender como os efeitos de futuridade (visto ser a criança considerada um vir-a-ser) e de proteção são produzidos no discurso sobre a criança.

É na instância do jurídico que o sujeito do capitalismo se constitui e não é fora dessa instância que a criança também é constituída como sujeito. Entretanto, algumas observações precisam ser apreciadas. A relação do adulto com a criança pauta-se em relações hierarquizadas de comando-obediência (LAGAZZI, 1988) nas quais a voz da criança não tem vez ou lugar. Quando falamos de obediência, referimo-nos à obediência à medicina, à psicológica, à pedagogia, ao direito que produzem discursos sobre a categoria criança. É uma relação tutelar, uma vez que a criança é instituída juridicamente como aquele que necessita de proteção e de preparação ${ }^{4}$.

Embora não se dê vez à voz da criança, são permitidos a ela o jogo com as palavras, as rimas, os trava-línguas, os chistes, a ambiguidade (colocada apenas como um problema de linguagem) em suma, não ter clareza em seu dizer. Todavia, a criança deve "aprender", via educação, vir a ser um sujeito ao mesmo tempo livre e submisso, detentor de direitos e cumpridor de deveres, autônomo e responsável. Essa, contudo, não seria tão somente uma questão de aprendizagem, mas, em termos discursivos, podemos compreender como assujeitamento à forma-sujeito histórica.

O ludicismo, tal como estamos propondo, perpassa a relação da criança-aluno, criança-não-trabalhador, criança-consumidor, com o jurídico, uma vez que é uma relação que não explicita o jurídico na constituição desse vir-a-ser-sujeito. Podemos dizer que o ludicismo está a serviço do aparato jurídico.

Vale sublinhar que o ludicismo não tem relação com o conceito de discurso lúdico desenvolvido por Orlandi (2003). Esse supõe o non sense, o real da língua. Pensamos o ludicismo no nível da 
constituição do discurso de divulgação científica para a criança. Dessa forma, os processos sócio-históricos e ideológicos ali se encontram. É uma relação imaginária - ou como aponta Orlandi (idem), o "faz de conta" que constitui a relação do jurídico com a criança, na qual criança é falada em um espaço de previsões.

A categoria criança é atravessada por vários dizeres, de várias ordens, mas, sobretudo, é atravessada pelos dizeres sobre a sua fragilidade, imaturidade, curiosidade, afetividade. Em suma, é atravessada pelo ludicismo de forma a ser assujeitada à forma-sujeito histórica.

\section{Algumas palavras finais}

Neste artigo, trabalhamos com os textos que apontam a dispersão do discurso sobre a criança, visto que tínhamos como objetivo compreender a categoria criança. Cumpre destacar que as análises foram realizadas a partir de um corpus composto por diferentes materialidades textuais. Para analisarmos a categoria criança retomamos as reflexões de Haroche (1992) e Orlandi (2002) sobre o sujeito-jurídico do capitalismo e os trabalhos realizados, sobretudo, no âmbito da história.

Observamos que, com a irrupção de um novo modo de produção, a criança foi associada a um período demarcado na linha do desenvolvimento humano, que é a infância. A criança, ou melhor, a categoria criança passou a ser falada em um espaço de previsões. A criança (ao menos a criança de uma determinada classe social) deixou de ocupar lugar na produção. Por extensão, por não trabalhar/fazer, a improdutividade foi imputada ao não-saber. Assim sendo, a criança passou a não fazer e a não saber. Essa condição a definiu como um de vir-a-ser-sujeito. Juridicamente, a criança não fala, mas é falada pela medicina, pela psicologia, pela pedagogia, pelo direito - campos autorizados a observar a criança, demarcar atitudes para distintas faixas etárias, pronunciar sobre seu desenvolvimento, etc. Uma outra questão mereceu destaque. $\mathrm{O}$ jogo (desvinculado da seriedade adulta) tornou-se, historicamente, imbricado nas práticas da criança. A "especialização do mundo infantil" produz consenso: a forma de falar a criança. A relação da categoria criança com o jurídico é marcada por um laço pautado no que denominamos ludicismo, uma relação de ordem imaginária, pautada pela futuridade, que faz funcionar uma determinada formulação do discurso sobre criança.

\footnotetext{
Abstract

This paper aims to investigate the way the discourse about children operates. It is based on the theoretical principles of French Discourse Analysis, on the tradition concocted by M. Pêcheux.
} 
Notions such as child as a category and ludicismo were proposed in an attempt to understand the way the meanings of subject-child are constituted to make sense through the discourses that circulate in our society. The survey has indicated that the discourse about the child is traversed by a ludicismo that implies the relationships established with the legal sphere, concealing it through playing and game. Ludicismo is also characterized by a projection of the child's future, the subject's will-be.

Keywords: Discourse about children; category; ludicismo

\section{REFERÊNCIAS}

ALTHUSSER, Louis. Aparelhos ideológicos do estado. $2^{\text {a }}$ ed. Rio de Janeiro: Graal, 1985.

ARIÈS, Philippe. História social da criança e da família. Rio de Janeiro: LTC, 1981.

BETTELHEIM, Bruno. A psicanálise dos contos de fadas. Rio de Janeiro: Paz e Terra, 1986.

BOTO, Carlota. O desencantamento da criança: entre a Renascença e o Século das Luzes. In: FREITAS, Marcos César; KUHLMANN JÚNIOR, Moysés (org.). Os intelectuais na história da infância. São Paulo: Cortez, 2002, p. 11-60.

FOUCAULT, Michel. A microfísica do poder. $23^{\mathrm{a}}$ ed. Rio de Janeiro: Graal, 2006.

As palavras e as coisas: uma arqueologia das ciências humanas. $9^{a}$ ed. São Paulo: Martins Fontes, 2007.

. Os anormais. $2^{\mathrm{a}}$ ed. São Paulo: Martins Fontes, 2001.

HAROCHE, Claudine. Fazer dizer, querer dizer. São Paulo: Ed. Hucitec, 1992.

LAGAZZI, Suzy. O desafio de dizer não. Campinas: Pontes, 1988.

MAUAD, Ana Maria. A vida das crianças de elite durante o Império. In: DEL PRIORE (org.). História das crianças no Brasil. $4^{\mathrm{a}}$ ed. São Paulo: Contexto, 2004, p. 137-178.

NOSELLA, Paolo. A linha vermelha do planeta infância: o socialismo e a educação da criança. In: FREITAS, Marcos César; KUHLMANN JÚNIOR, Moysés (org.). Os intelectuais na história da infância. São Paulo: Cortez, 2002, p. 129-166.

ORLANDI, Eni. Discurso e leitura. São Paulo: Cortez, 1999.

Análise de Discurso: princípios e procedimentos. $2^{\mathrm{a}}$ ed.

Campinas: Pontes, 2000. 
. Lingua e conhecimento linguístico: para uma história das ideias no Brasil. São Paulo: Cortez, 2002.

. A linguagem e seu funcionamento: as formas do discurso. $4^{\text {a }}$ ed. Campinas: Pontes, 2003.

- Interpretação: autoria, leitura e efeitos do trabalho simbólico. $4^{\mathrm{a}}$ ed. Campinas, SP: Pontes: Vozes, 2004.

O sujeito discursivo contemporâneo: um exemplo. In: INDURSKY, F.; Ferreira, M. C. L. (org.). Análise do discurso no Brasil. São Carlos: Claraluz, 2007a, p. 11-20.

. Educação em direitos humanos: um discurso. In: SILVEIRA, R. M. G. et al. Educação em direitos humanos: Fundamentos teóricos-metodológicos. João Pessoa: Editora Universitária, 2007b, p. 295-311.

PÊCHEUX, Michel. Semântica e discurso: uma crítica à afirmação do óbvio. Campinas. Editora da Unicamp, 1988.

. Análise automática do discurso. In: GADET, F. \& HAK, T. (org.). Por uma análise automática do discurso. Campinas: Editora da Unicamp, 1997, p 61- 162.

PERES, Ana Maria Clark. A criança e o estilo. In: O infantil na literatura: uma questão de estilo. Belo Horizonte: Miguelin, 1999, p. 22-68.

ROUSSEAU, Jean Jacques. Emílio, ou, da educação. $3^{a}$ ed. São Paulo: Martins Fontes, 2004.

SMOLKA, Ana Luíza Bustamante. Estatuto de sujeito, desenvolvimento humano e teorização sobre a criança. In: FREITAS, Marcos César; KUHLMANN JÚNIOR, Moysés (Org.). Os intelectuais na história da infância. São Paulo: Cortez, 2002, p. 99-128.

VORCARO, Angela. A criança na clínica psicanalítica. Rio de Janeiro: Companhia de Freud, 2004. 